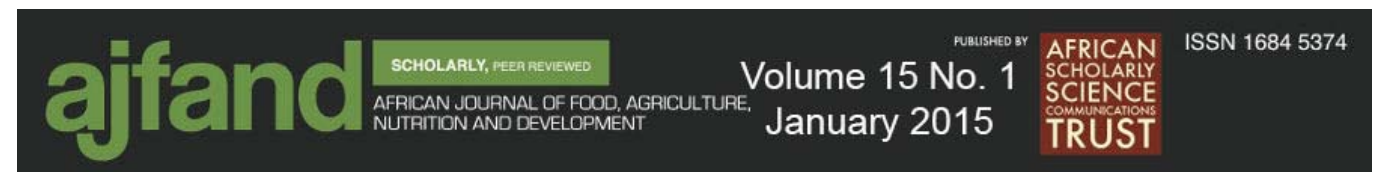

\title{
ROASTING EFFECTS ON PHENOLIC CONTENT AND FREE- RADICAL SCAVENGING ACTIVITIES OF PULP PRE- CONDITIONED AND FERMENTED COCOA (THEOBROMA CACAO) BEANS
}

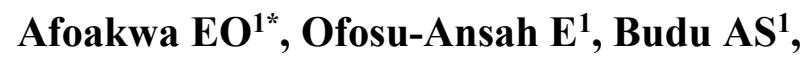 \\ Mensah-Brown $\mathrm{H}^{3}$ and JF Takrama ${ }^{2}$
}

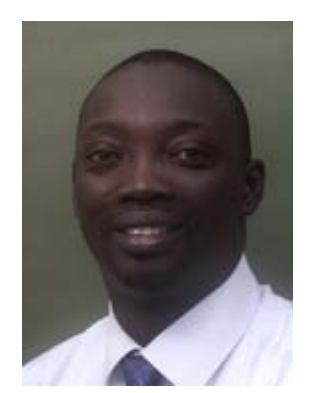

Emmanuel Afoakwa

*Corresponding author email: eafoakwa@ug.edu.gh / eoafoakwa@gmail.com

${ }^{1}$ Department of Nutrition \& Food Science, University of Ghana, P. O. Box LG 134 Legon-Accra, Ghana

${ }^{2}$ Cocoa Research Institute of Ghana, P. O. Box 8, New Tafo - Akim, Eastern Region, Ghana

${ }^{3}$ Department of Food Process Engineering, University of Ghana, Legon-Accra, Ghana 


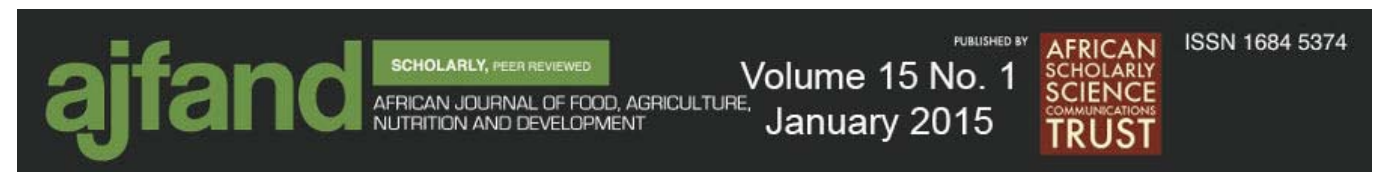

\section{ABSTRACT}

Polyphenols are phytochemicals responsible for the astringency, bitterness, green flavours and antioxidant activities in Theobroma cacao beans. Polyphenols degradation in cocoa beans during roasting is crucial to the flavour outcome and it is influenced by factors such as temperature, time and pod storage. Antioxidants are compounds that help to inhibit oxidation reactions caused by free radicals such as singlet oxygen, superoxide, peroxyl radicals, hydroxyl radicals and peroxynitrite thereby preventing damage to the cells and tissues. Their mechanisms of action include scavenging reactive oxygen and decreasing localised oxygen concentration thereby reducing molecular oxygen's oxidation potential, metabolising lipid peroxides to non-radical products and chelating metal ions to prevent generation of free radicals in humans. The study aimed at investigating changes in total polyphenols, anthocyanins, $O$-diphenols and antioxidant activity (free-radical scavenging activities) after roasting of pulp preconditioned and fermented cocoa beans using standard analytical methods. A $4 \times 4$ full factorial design with the principal experimental factors as pod storage time $(0,3,7$ and 10 days) and roasting duration $(0,15,30$ and 45 minutes $)$ at $120^{\circ} \mathrm{C}$ were used to study the changes in the total polyphenols, anthocyanins, $o$-diphenols and \% free-radical scavenging activities of the cocoa beans. Variable decrease in total polyphenols, $O$ diphenols and anthocyanins were observed with increase in pre-conditioning (pod storage time) and roasting duration. However, variable trends were observed for the $\%$ free-radical scavenging activities. The total polyphenols, anthocyanins and $o$-diphenols in the cocoa beans after 45 minutes roasting decreased in the range 132.24 to 57.17 $\mathrm{mg} / \mathrm{g}, 6.71$ to $1.07 \mathrm{mg} / \mathrm{kg}$ and 15.94 to $8.25 \mathrm{mg} / \mathrm{g}$ respectively at all pod storage treatments. The total polyphenols of the fermented, dried and unstored (freshly harvested) cocoa beans was $132.25 \mathrm{mg} / \mathrm{g}$ which reduced to $122.14 \mathrm{mg} / \mathrm{g}(7.6 \%$ degradation), $116.721 \mathrm{mg} / \mathrm{g}$ (11.7\% degradation) and $92.22 \mathrm{mg} / \mathrm{g}$ (30.3\% degradation) after storage for 3, 7 and 10 days, respectively. The optimum decrease in the $\%$ freeradical scavenging activity was 7 days and above of pods storage. Increasing roasting time caused a continuous decrease in the \% free-radical scavenging activity from $89.10 \%$ to $74.31 \%$ after 45 minutes for beans from the unstored (freshly harvested) pods. However, pod storage caused an increase in the \% free radical scavenging activities during roasting. Pulp pre-conditioning (pod storage) and roasting duration could be used to reduce the astringency and bitterness caused by polyphenols, $O$ diphenols and anthocyanins in cocoa beans as well as increase the antioxidant activity imparted by cocoa.

Key words: Cocoa, pod storage, roasting, polyphenols 


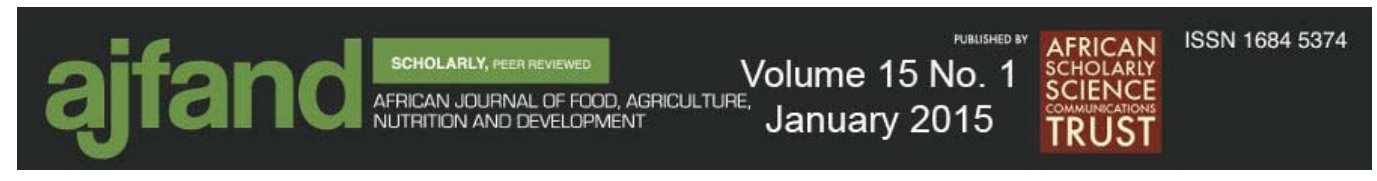

\section{INTRODUCTION}

Theobroma cacao (cocoa) is a rich source of phytochemicals with polyphenols and alkaloids being predominant. Polyphenols in cocoa has gained much attention recently due to their antioxidant activity and health benefits in the prevention and treatment of cancer (free-radical scavenging activities) [1], cardiovascular diseases and other pathologies [2]. The phenolic content and concentration in raw cocoa beans depend on the variety of cocoa bean (genotype), degree of ripeness, processing and storage [3]. About $12-18 \%$ of the dry weight of the whole cocoa bean consists of polyphenols and is associated with the flavour, colour and antioxidant activities of cocoa products such as chocolate [4]. Polyphenol content of $10 \%$ or more is considered a sign of bad fermentation since it affect flavour outcome during roasting $[1,3,5]$. The polyphenol content of 12 to $18 \%$ dry weight in the whole bean is valid for Forastero beans [1]. Criollo cocoa beans contain approximately two-third of the amount of polyphenols, while anthocyanins are absent $[1,3]$.

The polyphenols (10-20\% dry bean weight) are stored in the pigment cells or polyphenolic cells of the cotyledons together with the alkaloids caffeine, theobromine and theophylline [6]. Polyphenols form complexes with protein, polysaccharide and alkaloid. Hydrogen and hydrophobic bonding are involved in the protein-polyphenol interaction [7]. This causes salivary proteins in the oral cavity to precipitate giving polyphenols their astringent character.

In cocoa, three groups of polyphenols are identified, these are catechins or flavan-3-ols $(37 \%$ or $370 \mathrm{~g} / \mathrm{kg})$, anthocyanins $(4 \%$ or $40 \mathrm{~g} / \mathrm{kg})$ and proanthocyanidins or leucoanthocyanins $(58 \%$ or $580 \mathrm{~g} / \mathrm{kg})$ [6]. The main flavan-3-ol is (-)-epicatechin and makes up 35\% of the polyphenol content in the cocoa beans [1]. Small amounts of $(+)-$ catechin and traces of (+)-gallocatechin and (-)-epigallocatechin are also present as well as other minor flavanol constituents such as quercitin, quercitin-3-glucoside (isoquercitin), quercetin-3-O-arabinoside and quercitin-3-galactoside (hyperoside) [6]. The main fractions of anthocyanin in cocoa beans are cyanidin-3- $\alpha$-L-arabinoside and cyanidin-3- $\beta$-D-galactoside $[3,7]$. Other anthocyanins such as cyanidin-3-O-glucoside are also present [8].

Polyphenols are modified or degraded to an extent during fermentation, drying and roasting affecting the antioxidant activity. The extent of degradation or loss of the phenolics depends on the stage of processing. Fermentation reduces the polyphenol content of cocoa beans viz., flavan-3-ols, anthocyanins and proanthocyanidins by modifications and reacting with other compounds. Polyphenol oxidase (PPO), a copperdependent enzyme present in the cocoa beans, catalyzes two different reactions in the presence of oxygen, namely, the hydroxylation of monophenols to $o$-diphenols (monophenolase activity) and the oxidation of $o$-diphenols to $o$-quinones (diphenolase activity) [9]. These results in the modification of the phenolic content of the beans leading to the reduction in the bitterness and astringency of the cocoa beans as well as development of the typical brown cocoa bean colour [5]. 


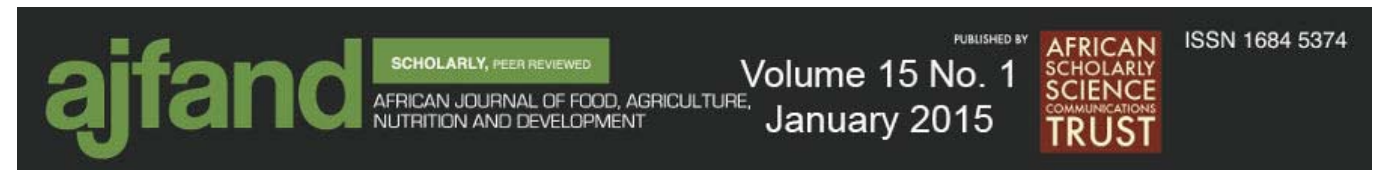

The activities of polyphenol oxidase (monophenolase and diphenolase) are reported to be facilitated during the aerobic phase of fermentation when most of the pulp on the beans is degraded, subcellular membranes are broken down as well as turning of the fermenting bean mass [10]. Pulp pre-conditioning (pod storage) was reported to increase micro-aeration of the fermenting mass by reducing the pulp volume per seed due to water evaporation and sucrose inversion [11]. This technique is expected to influence the activity of polyphenol oxidase and the content of polyphenols, anthocyanin, $O$-diphenols and antioxidant activities.

Polyphenols degradation in cocoa beans during roasting has been reported to be affected by temperature and time especially the higher oligomers viz., epicatechins and anthocyanins $[1,9]$. Increasing processing temperature and/or roasting time result in increasing degradation rate of polyphenols in cocoa beans and thus lower the residual polyphenols retained in the beans [1]. Other factors such as postharvest treatment (pod storage) have been reported to determine the choice of roasting conditions and improve the flavour outcome [3]. However, the extent to which this technique alters the degradation rate of polyphenols, anthocyanins and $o$-diphenols and antioxidant activity (free-radical scavenging activities) in Ghanaian cocoa beans during roasting remains unknown. Thus, the aim of this study was to establish the effect of roasting on the total polyphenols, anthocyanins, $O$-diphenols and antioxidant activity of pulp preconditioned and fermented cocoa beans.

\section{MATERIALS AND METHODS}

\section{Raw materials}

Fully ripe mixed hybrid variety (Amelonado and Amazonica hybrids) was obtained from the cocoa plantation of the Cocoa Research Institute of Ghana (CRIG), New-Tafo in the Eastern Region of Ghana.

\section{Experimental design}

A $4 \times 4$ full factorial design with the principal experimental factors as pod storage $(0,3$, 7 and 10 days) and roasting time $(0,15,30$ and 45 minutes $)$ at $120^{\circ} \mathrm{C}$ were used to study the changes in the total polyphenols, anthocyanins, o-diphenols and \% free-radical scavenging activities of the cocoa beans. The pods were stored under ambient temperature $\left(25-31^{\circ} \mathrm{C}\right)$ and relative humidity of $85-100 \%$.

\section{Sample preparation}

Fresh and fully ripe cocoa pods were harvested, sorted out to remove the bruised ones and divided into four parts, each containing three hundred (300) pods. The pods were stored in heaps for four different storage times ( $0,3,7$ and 10 days) on the bear concrete floor under shade and broken after the specified days of storage. The beans were scooped out and fermented for six days using the basket fermentation technique. About $30 \mathrm{~kg}$ of extracted cocoa beans were placed in woven baskets lined with banana leaves. The top of the heaps were also covered with banana leaves and the beans fermented for six days with consecutive opening and turning every $48 \mathrm{~h}$. The fermented cocoa beans were sun dried under ambient temperatures $\left(25-32^{\circ} \mathrm{C}\right)$ and relative humidity of 85 $100 \%$ with stirring four times each day to allow uniform drying of the beans. 


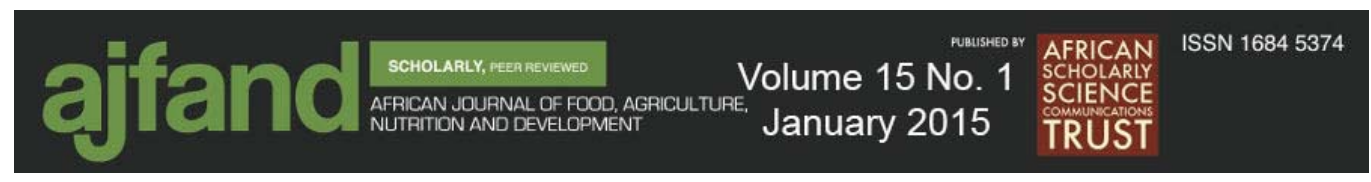

Cocoa samples were randomly picked at intervals and moisture content analysed until moisture content of between 5.5 to $6 \%$ was attained. The cocoa beans were immediately packaged in air tight black plastic bags prior to roasting. Roasting was done according to the method of Owusu [12] with slight modifications. The fermented and dried mixed hybrid cocoa beans packaged in air tight black plastic bags were sorted to remove all the flat beans. About $500 \mathrm{~g}$ of the beans was weighed and roasted using hot air oven in batches at a temperature of $120^{\circ} \mathrm{C}$ for $0,15,30$, and 45 minutes. For each of the roasting treatments under investigation, the oven temperature was set at $120^{\circ} \mathrm{C}$ and left to equilibrate for at least 30 minutes. The fermented dried cocoa beans $(500 \mathrm{~g})$ were spread in a single layer in the perforated metallic sample tray and then placed on the oven shelf close to the thermometer.

After roasting, the cocoa beans were transferred to another tray and allowed to cool to room temperature and placed in air tight black plastic bags according to the duration of pod storage and roasting. The samples were stored at ambient temperature $\left(25-28^{\circ} \mathrm{C}\right)$ in a dark room free from strong odours until used. The procedure was repeated for the different pulp pre-conditioning treatments. The cocoa beans were shelled manually using a knife and milled using kitchen blender for further analyses. All treatments were conducted in duplicates.

\section{METHODS AND PROCEDURES}

\section{Total polyphenols}

Total polyphenols of the nibs was determined using the Folin-Ciocalteu method [13]. Exactly $0.2 \mathrm{~g}$ of defatted cocoa sample was weighed into a fulcrum tube and $30 \mathrm{ml}$ of methanol: $\mathrm{HCl}(80 \%: 1 \%, \mathrm{v} / \mathrm{v})$ added. The fulcrum tube with the sample was placed on the orbital shaker and timed for 2 hours at $420 \mathrm{rpm}$. The supernatant was decanted slowly into another fulcrum tube at the end of the 2 hours of extraction. $1 \mathrm{ml}$ of the supernatant was diluted using $9 \mathrm{ml}$ of $80 \%$ methanol in a fulcrum tube. Exactly $1 \mathrm{ml}$ of the diluted sample was pipetted into a labelled test tube and $5 \mathrm{ml}$ of $10 \%$ FolinCiocalteu reagent, $4 \mathrm{ml}$ of $0.075 \mathrm{~g} \mathrm{ml}^{-1}$ sodium bicarbonate solution added. The sample was allowed to stand at room temperature for an hour and then placed in the freezer (temperature $-17^{\circ} \mathrm{C}$ ) for another 1 hour. Absorbance was taken at $760 \mathrm{~nm}$ using UV/Visible spectrophotometer (Beckman Coulter spectrophotometer, Model Du 730, Birmingham, UK) equipped with one centimeter curvette. Catechin solution prepared at different concentrations ( 0 to $100 \mu \mathrm{g} / \mathrm{ml}$ ) was used to plot a standard curve. The total polyphenols content of the samples were obtained by extrapolating their absorbance values on the standard curve and expressed as mg catechin equivalents.

\section{Anthocyanins}

Anthocyanin content of the nibs was determined using reported method with slight modifications [14]. The extracts obtain for the polyphenol analysis was filtered using No.4 Whatman paper and total absorbance (TOD) read at $535 \mathrm{~nm}$ using UV/Visible spectrophotometer (Beckman Coulter spectrophotometer, Model Du 730, Tokyo, Japan) equipped with one centimeter curvette. The anthocyanin content of the samples was calculated as; 


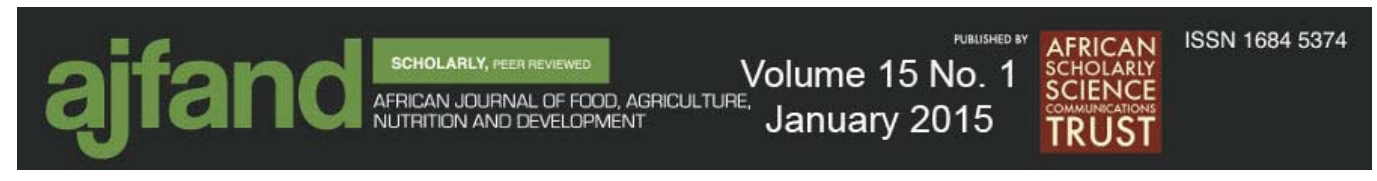

Total anthocyanin $(\mathrm{mg} / \mathrm{kg})=\mathrm{TOD} \times 1000 /($ Ave 535$){ }^{1 \%} 1 \mathrm{~cm} / 10$

Where;

$\mathrm{TOD}=$ total optical density (absorbance) and (AvE530) $1 \mathrm{~cm}$ is the average extinction coefficient for total anthocyanin when $1 \mathrm{~cm}$ cuvette and $1 \%\left(10 \mathrm{mg} \mathrm{ml}^{-1}\right)$ standards was used; the value is 982 .

\section{O-diphenols}

The Arrow's reagent was prepared using $10 \mathrm{~g} \mathrm{NaNo}$, and $10 \mathrm{~g} \mathrm{Na} 2 \mathrm{MoO}_{4}$ in $100 \mathrm{ml}$ $\mathrm{H}_{2} \mathrm{O}$. The extracts obtain for the polyphenol analysis were used for the $o$-diphenols determination. $1 \mathrm{ml}$ of the extract was pipette into a test tube and $1 \mathrm{ml}$ of $0.5 \mathrm{~N} \mathrm{HCl}$, $1 \mathrm{ml}$ arrow's reagent, $10 \mathrm{ml}$ deionised water $\left(\mathrm{dH}_{2} \mathrm{O}\right)$ and $2 \mathrm{ml}$ of $1 \mathrm{M} \mathrm{NaOH}$ were added. Absorbance of the mixture was read at $520 \mathrm{~nm}$ after 30 seconds using UV/Visible spectrophotometer (Beckman Coulter spectrophotometer, model Du 730, Birmingham, UK). Cathechol solutions prepared at different concentrations $(0,20,60,80$, and 100 $\mu \mathrm{g} \mathrm{ml}^{-1}$ ) were used as the standard to draw the standard curve. The $o$-diphenol $(o-$ dihydric) content of the samples were obtained by extrapolating their absorbance values on the standard curve and expressed as cathechol per gram of cocoa nibs.

\section{Antioxidant activity (free-radical scavenging activity) using DPPH assay}

The radical scavenging activity was estimated using Othman et al. [15] method with modifications. The extracts for the polyphenol analysis was used for the antioxidant activity. $3.8 \mathrm{ml}$ of $0.2 \mathrm{M} \mathrm{DPPH}$ solution in ethanol was added to $0.2 \mathrm{ml}$ of the polyphenol extract. The mixture was placed in the dark room at room temperature for 20 minutes. The absorbance of the mixture was read at $517 \mathrm{~nm}$ using UV/Visible spectrophotometer (Beckman Coulter spectrophotometer, model Du 730) equipped with one centimeter curvette.

The percentage radical scavenging activity was calculated using the following equation:

Scavenging Activity $(\%)=\left[\frac{\text { Absorbance of control- Absorbance of sample at } 517 \mathrm{~nm}}{\text { Absorbance of control at } 517 \mathrm{~nm}}\right] \times 100$

Statistical analyses

The data were analyzed using Statsgraphics software version 15.0 (STSC, Inc., Rockville, MD, USA) for Analysis of variance (ANOVA) at $p<0.05$. The combined effect of pod storage and roasting duration were studied using the response surface methodology. Models were developed to relate pod storage and roasting duration on the studied parameters. The coefficients of the variables in the models and their contribution to the model's variation were determined. $\mathrm{R}^{2}$ values were used to judge the adequacy of the models. For a good fit of a model, an $\mathrm{R}^{2}$ of at least $60 \%$ was used. The $\mathrm{R}^{2}$ of a model refers to the proportion of variation in the response attributed to the model rather than random error. 


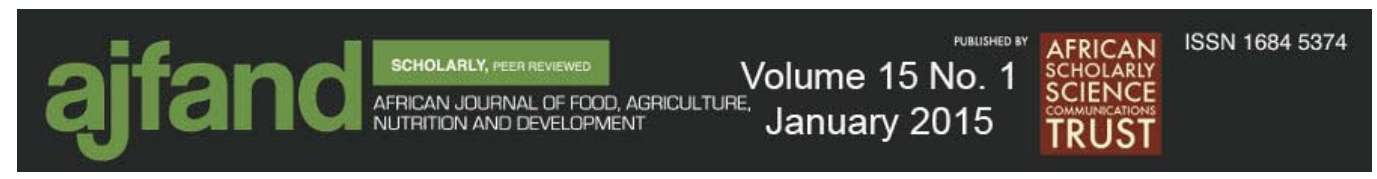

\section{RESULTS}

\section{Changes in total polyphenols in the cocoa beans}

The polyphenolic content of the cocoa beans decreased as the duration of cocoa pod storage increased from 0 to 10 days. The total polyphenols for unstored cocoa beans was $132.25 \mathrm{mg} \mathrm{g}^{-1}$ which reduced to $122.14 \mathrm{mg} \mathrm{g}^{-1}$ (7.6\% degradation), $116.721 \mathrm{mg} \mathrm{g}^{-}$ 1 (11.7\% degradation) and $92.22 \mathrm{mg} \mathrm{g}^{-1}$ (30.3\% degradation) for pod stored for 3,7 and 10 days respectively. The response surface curve indicated that the optimum pod storage day for degradation of polyphenols was 7 days and above (Figure 1).

The response surface plot (Figure 1) showed that increasing the duration of roasting significantly $(\mathrm{p}<0.05)$ reduced the total polyphenols of the cocoa beans at all pod storage periods. It also decreased from $122.14 \mathrm{mg} \mathrm{g}^{-1}$ to $76.40 \mathrm{mg} \mathrm{g}^{-1}, 116.72 \mathrm{mg} \mathrm{g}^{-1}$ to $78.28 \mathrm{mg} \mathrm{g}^{-1}$ and $92.22 \mathrm{mg} \mathrm{g}^{-1}$ to $57.18 \mathrm{mg} \mathrm{g}^{-1}$, respectively after 45 minutes roasting for pods stored for 3, 7 and 10 days.

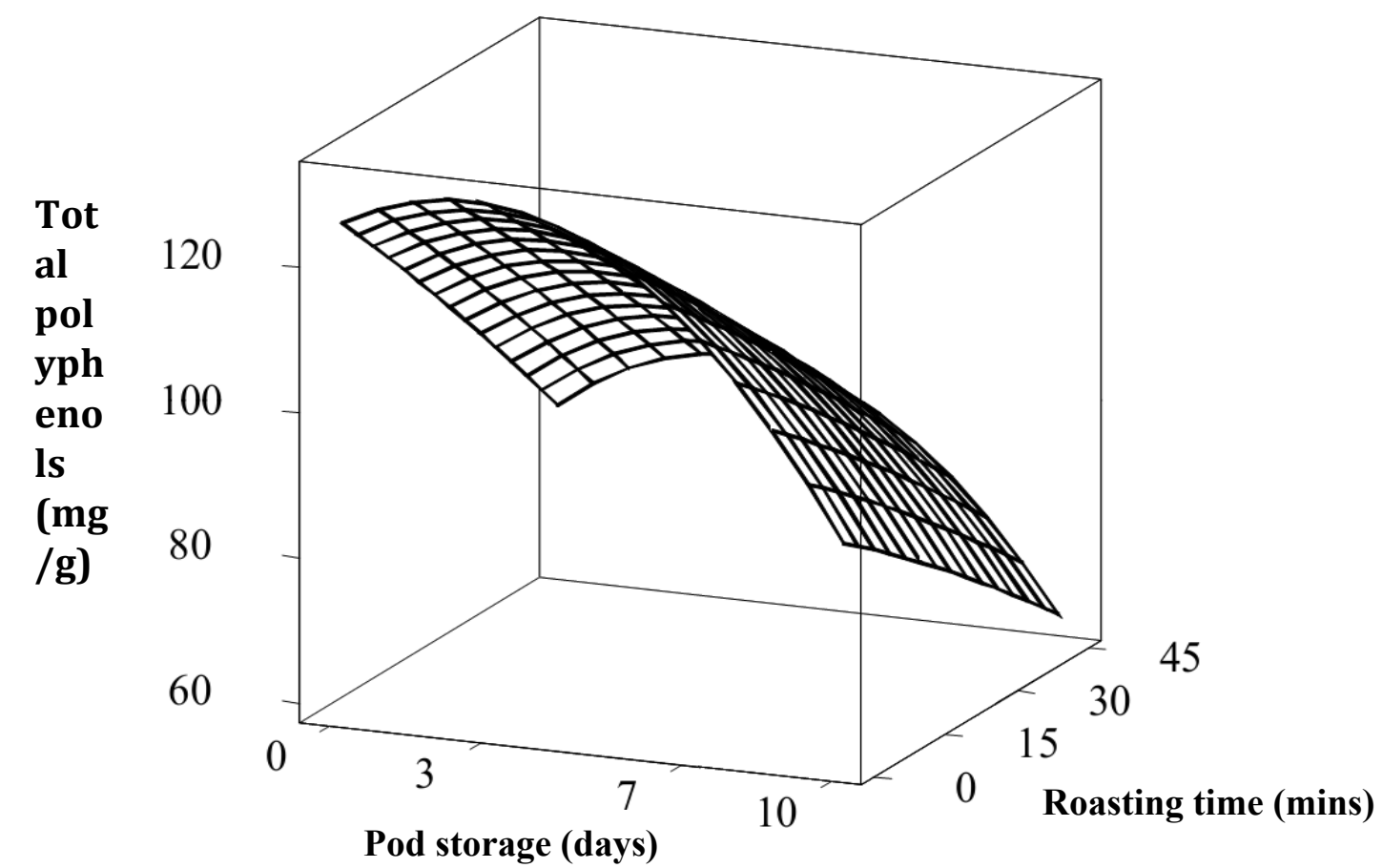

Figure 1: Effect of pod storage and roasting time on the total polyphenols in the cocoa beans

The regression model developed to predict the effect of pod storage and roasting time on the polyphenolic content of the cocoa nibs showed a statistically significant influence of the linear factors for pod storage and roasting time at $\mathrm{p}<0.05$ (Table 1). The quadratic factor for pod storage was also significant $(\mathrm{p}<0.05)$ whiles that of roasting time was insignificant $(p>0.05)$ on the total polyphenols (Table 1). The interaction effect of pod storage and roasting time significantly $(p<0.05)$ influence the total polyphenol content of the beans (Table 1). The regression model could explain 


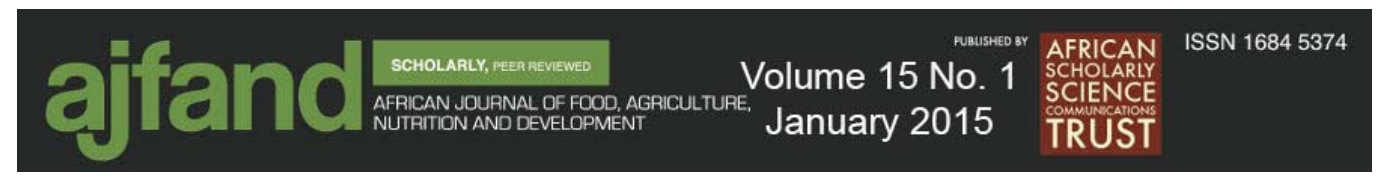

$85.9 \%$ of the variations that existed in the total polyphenol content of the cocoa beans due to pod storage and roasting time as indicated by the $\mathrm{R}^{2}$ value (Table 1 ). This means, $14.1 \%$ of the variation in the model was due to other effects. Response surface curve (Figure 1) showed a curvilinear relationship for roasting time and total polyphenols at all pod storage treatments.

\section{Changes in anthocyanins}

Changes in the anthocyanins content of the beans during pod storage are shown in Figure 2. Anthocyanin content in the cocoa beans decreased with increasing duration of pod storage from 0 to 10 days. It decreased from $6.7133 \mathrm{mg} \mathrm{kg}^{-1}$ for the unstored pods to $6.3442 \mathrm{mg} \mathrm{kg}^{-1}$ (5\% reduction) for pods stored for 3 days, $4.5189 \mathrm{mg} \mathrm{kg}^{-1}$ (33\% reduction) for pods stored for 7 days and $4.3964 \mathrm{mg} \mathrm{kg}^{-1}$ (35\% reduction) for pod stored 10 days after fermentation and drying.

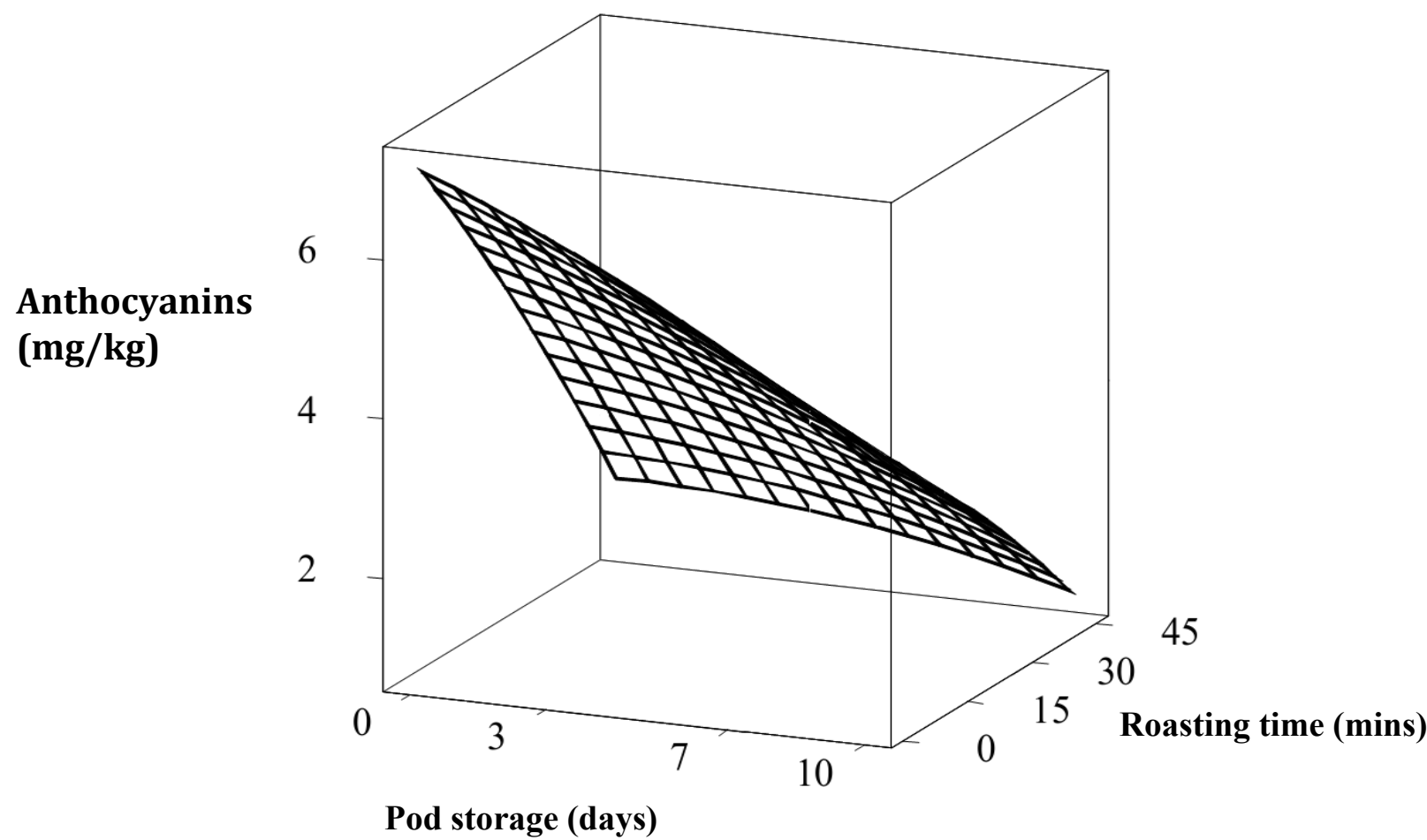

Figure 2: Effect of pod storage and roasting time on the anthocyanins in the cocoa beans

Results also showed that anthocyanin content in the cocoa beans decreased significantly $(\mathrm{p}<0.05)$ during roasting for all pod storage treatments (Table 1$)$. The anthocyanin content in the fermented and dried cocoa beans of the unstored pods decreased from $6.713 \mathrm{mg} \mathrm{kg}^{-1}$ at the start of roasting to $1.210 \mathrm{mg} \mathrm{kg}^{-1}$ after 45 minutes of roasting. Similar trend of decrease was observed for beans whose pulp were pre-conditioned where anthocyanin content decreased from $6.344 \mathrm{mg} \mathrm{kg}^{-1}$ to $2.072 \mathrm{mg} \mathrm{kg}^{-1}, 4.519 \mathrm{mg}$ $\mathrm{kg}^{-1}$ to $1.419 \mathrm{mg} \mathrm{kg}^{-1}$ and $4.396 \mathrm{mg} \mathrm{kg}^{-1}$ to $1.070 \mathrm{mg} \mathrm{kg}^{-1}$, respectively for pods stored for 3, 7 and 10 days after 45 minutes of roasting (Figure 2). 


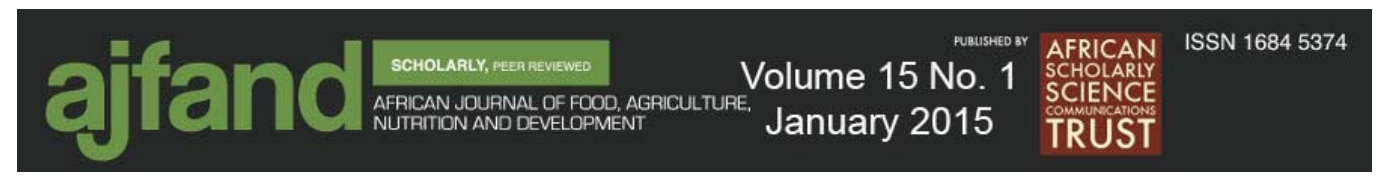

The coefficients of the regression model developed to predict the effect of pod storage and roasting time on the anthocyanins of the cocoa nibs showed a significant $(p<0.05)$ influence of the linear factors for pod storage and roasting time (Table 1) whiles, the quadratic factors for pod storage and roasting time insignificantly $(p>0.05)$ influence the anthocyanins (Table 1). The interaction effect of pod storage and roasting time significantly $(\mathrm{p}<0.05)$ influence the anthocyanins in the cocoa nibs (Table 1$)$. The response surface plot developed (Figure 2) showed a rapid degradation of the anthocyanins in the cocoa bean with increasing roasting time compared to pod storage. The regression model could explain $92.6 \%$ of the variations that existed in the anthocyanins of the cocoa beans due to pod storage and roasting time as indicated by the $\mathrm{R}^{2}$ (Table 1 ). This means, $7.4 \%$ of the variation in the model was due to other effects.

\section{Changes in o-diphenols}

The $o$-diphenols content of the fermented and dried cocoa beans decreased as the duration of the pod storage increased from 0 to 10 days (Figure 3 ). It decreased from $15.94 \mathrm{mg} \mathrm{g}^{-1}$ for the unstored pods to $15.3574 \mathrm{mg} \mathrm{g}^{-1}$ for pods stored for 3 days and further decreased to $13.73 \mathrm{mg} \mathrm{g}^{-1}$ and $10.70 \mathrm{mg} \mathrm{g}^{-1}$ for pods stored for 7 and 10 days, respectively.

Roasting process caused significant $(\mathrm{p}<0.05)$ decrease in the $o$-diphenols content of the beans at all pod storage periods (Figure 3 ). The $o$-diphenols in the fermented and dried cocoa beans of the unstored pods decreased from $15.94 \mathrm{mg} \mathrm{g}^{-1}$ at the start of roasting to $10.71 \mathrm{mg} \mathrm{g}^{-1}$ after roasting for 45 minutes. Similar trend of decrease was observed for all pod storage treatments.

\section{$O$-diphenols \\ (mg/g)}

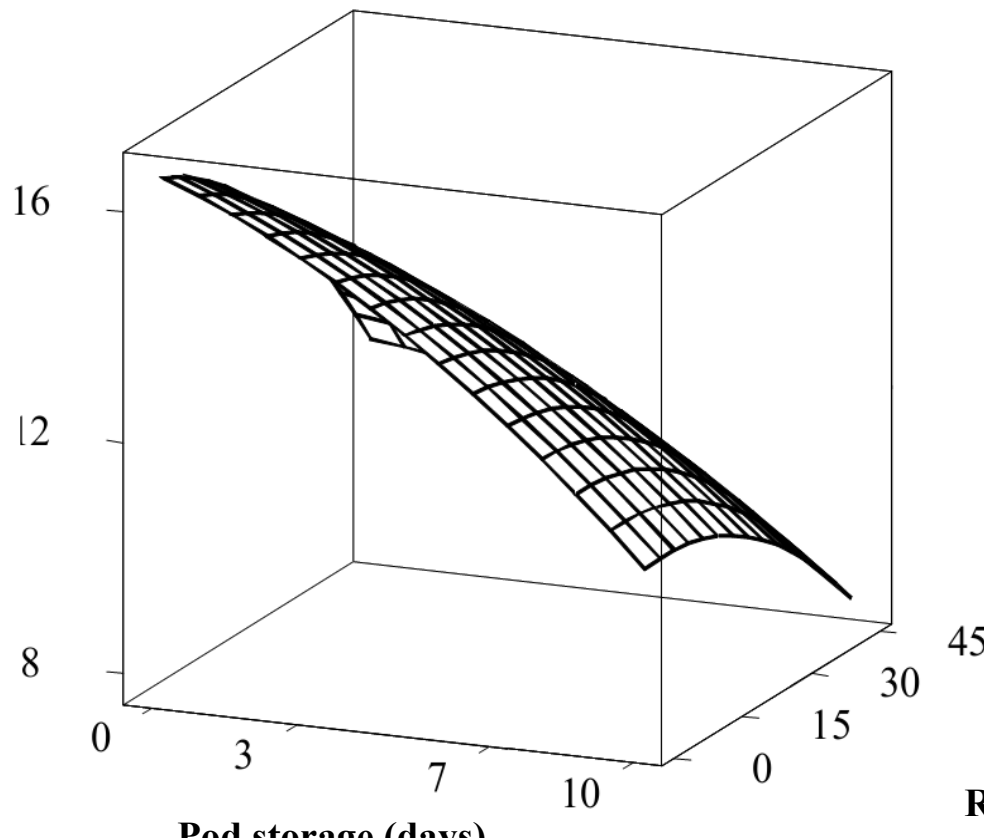

45

Roasting time (mins)

Figure 3: Effect of pod storage and roasting time on the o-diphenols in the cocoa beans 


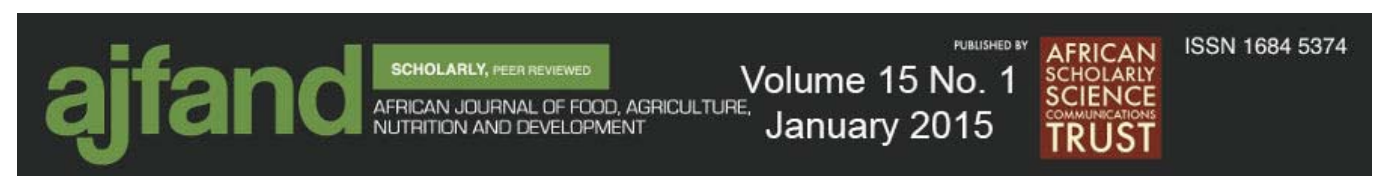

Regression model developed for the effect of pod storage and roasting time on the $o$ diphenols of the cocoa nibs showed significant $(p<0.05)$ influence of the linear factors for pod storage and roasting time (Table 1). The quadratic factor for pod storage insignificantly $(\mathrm{p}>0.05)$ influenced the $o$-diphenols whiles that of roasting time significantly $(\mathrm{p}<0.05)$ influenced the $o$-diphenols in the cocoa beans (Table 1$)$ as well as the interaction between pod storage and roasting time. The model developed could explain about $83 \%$ of the variations in the $o$-diphenols of the cotyledons, suggesting that $17 \%$ of the variations were due to other factors not investigated in this work (Table $1)$.

\section{Changes in the antioxidant activity (\% radical scavenging activity) of the cocoa beans}

The antioxidant activity (\% radical scavenging activity) of the cocoa samples determined by the 1, 1-diphenyl-2-picrihydrazyl (DPPH) assay showed a significant $(p<0.05)$ decrease in the $\%$ radical scavenging activity of the fermented and dried cocoa beans with increasing pod storage. The percentage radical scavenging activity of the beans for the unstored pods was $89.10 \%$ which increased slightly to $89.23 \%$ for pods stored for 3 days and further decreased to $82.18 \%$ and $73.97 \%$, for pods stored for 7 and 10 days, respectively. The response surface curve indicated that the optimum decrease in the $\%$ free-radical scavenging activity was 7 days and above for pods storage (Figure 4).

Roasting cocoa beans from the unstored pods at $120^{\circ} \mathrm{C}$ decreased the percentage radical scavenging activity from $89.10 \%$ to $74.31 \%$ after 45 minutes of roasting. However, pod storage caused an increase in \% free-radical scavenging activities during roasting. The $\%$ free-radical scavenging activities increased from $89.23 \%$ at the start of roasting to $90.68 \%$ for pods stored for 3 days. It also increased from $82.18 \%$ to $82.26 \%$ for pods stored for 7 days and $73.97 \%$ to $74.86 \%$ for pods stored for 10 days after 45 minutes of roasting (Figure 4). 

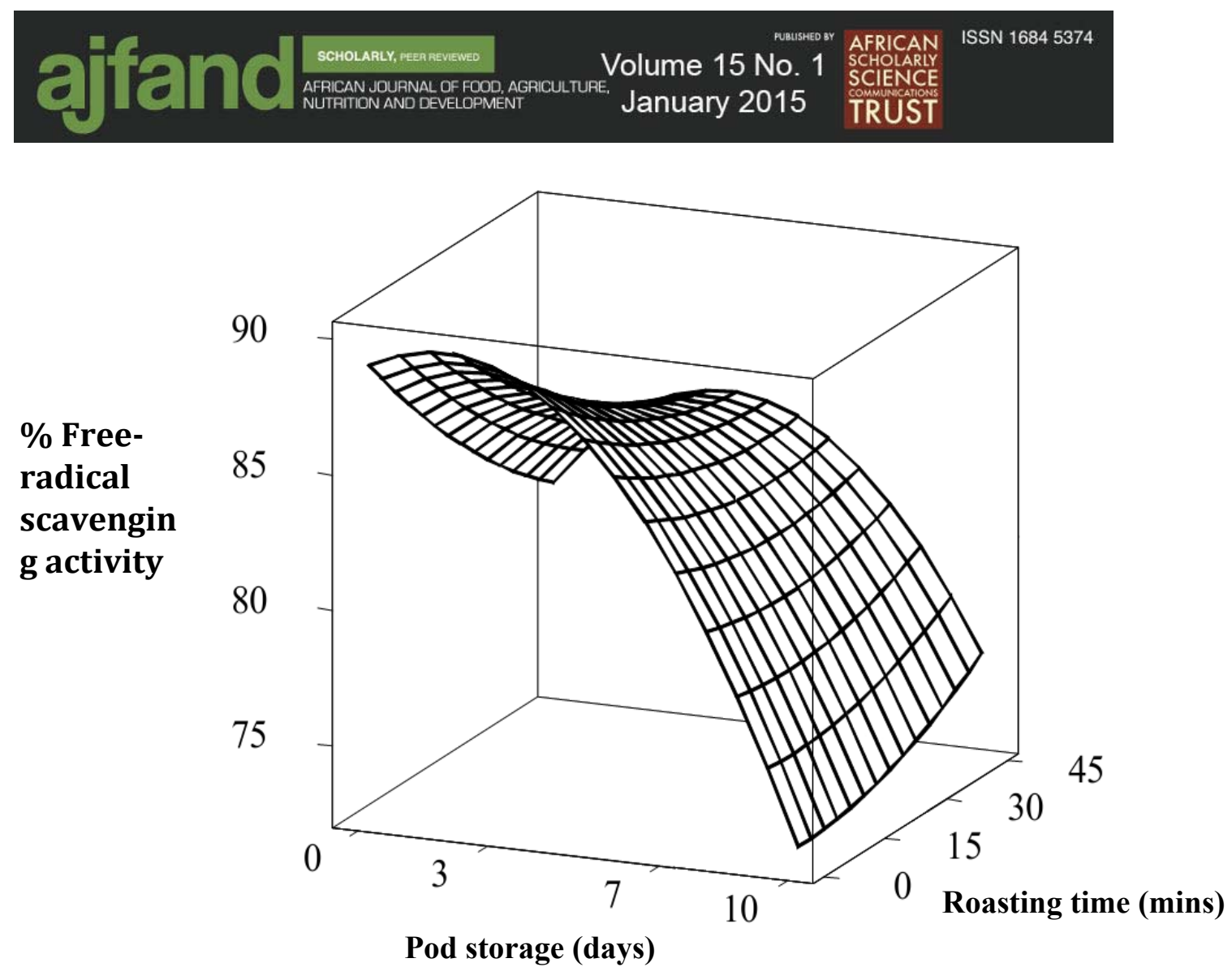

Figure 4: Effect of pod storage and roasting time on the $\%$ free-radical scavenging activity

The regression model developed for the effect of pod storage and roasting time on the $\%$ free-radical scavenging activity of the cocoa nibs showed a significant $(p<0.05)$ influence of the linear factor for pod storage and roasting time on the $\%$ free-radical scavenging activity of the cocoa nibs (Table 1). The quadratic factor for pod storage was also significant $(p<0.05)$ whiles that of roasting time insignificantly $(p>0.05)$ influence the $\%$ free-radical scavenging activity (Table 1$)$. The interaction factor for pod storage and roasting time significantly $(\mathrm{p}<0.05)$ influence the $\%$ free-radical scavenging activities (Table 1). A curvilinear relationship for roasting time and $\%$ freeradical scavenging activities at all pod storage treatments was observed (Figure 4). The trend of the graph (Figure 4) was similar to that of the total polyphenols (Figure 1). An $\mathrm{R}^{2}$ of $66.6 \%$ (Table 1) was observed, implying that about $67 \%$ of the variations in the $\%$ free-radical scavenging activities of the nibs could be explained by the model whiles the remaining 33\% was due to other factors not investigated in this work (Table 1).

\section{DISCUSSION}

\section{Changes in total polyphenols in the cocoa beans}

During roasting, temperature and time are major factors that affect the degradation rate of polyphenols especially the higher oligomers viz. epicatechins, anthocyanins $[1,9]$. The higher the processing temperature and or the longer the roasting time, the faster the degradation rate of the polyphenols in the cocoa beans and the lower the residual polyphenols retained in the beans [1]. This is because polyphenols have high redox- 


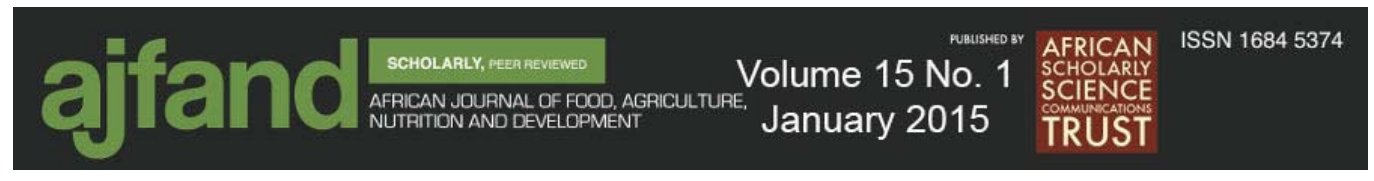

activity hence, tend to be oxidized rapidly in the presence of high temperature and oxygen into $o$-diphenols and then quinones $[1,16]$, which then polymerized with other molecules such as proteins, amino acids, sugars and other polyphenols.

The results corroborate earlier findings by Nazaruddin et al. [3] and Afoakwa et al. [17]. The decrease in polyphenols with increasing pod storage might be due to the reduction in pulp volume with an increase in aeration which might have enhanced the activities of polyphenol oxidase resulting in rapid oxidation and polymerization of (-)epicatechin and its oxidative products during fermentation [18]. The decrease in polyphenols with increasing roasting duration might be due to the susceptibility of polyphenols to thermal oxidation into $o$-quinones. The $o$-quinones then react with amino acids, proteins and sugars to form the brown colour and reduce their astringency [19]. This observation was in agreement with findings by Delonga et al. [20], where they observed $14 \%$ reduction in total polyphenols after 20 minutes of roasting of cocoa beans at $150^{\circ} \mathrm{C}$. Summa et al. [21] observed a progressive decrease in the concentration of reducing substances (polyphenols) in cocoa beans during pre-roasting and roasting.

\section{Changes in anthocyanins}

Anthocyanins are highly reactive in nature and as a result, degrade readily to form colourless or brown coloured compounds during processing such as fermentation, drying, alkalisation and roasting [22]. The decrease in the anthocyanin content of the cocoa beans with pod storage might be due to the activities of glycosidase. The degradation of the anthocyanins with roasting might be due to cleavage of the covalent bonds in the anthocyanin molecules during thermal oxidation to form aglycone which then undergo thermal oxidation to form quinones that polymerize with proteins, sugars and other polyphenols $[8,23]$.

There were consistent degradation of anthocyanins in the cocoa beans with increasing roasting time. The results showed about $20-25 \%$ reduction in the anthocyanin content of the beans after every 15 minutes of roasting. These decreases in anthocyanin concentrations in the cocoa beans with increasing roasting time might be due to the polymerization reactions between 5-hydroxymethylfurfural (HMF) and the anthocyanins and also to a lesser extent, the hydrolytic mechanisms, since HMF formation and polymerization are enhanced at low moisture content [23-24]. The extent of the anthocyanins degradation was dependent on the roasting duration and the magnitude of the heating of the product $[8,25]$.

\section{Changes in o-diphenols}

The decrease in $o$-diphenols with increasing pod storage might be due to the reduction in pulp volume with an increase in aeration which might have enhanced the activities of diphenolase in the cotyledons to oxidize the $o$-diphenols to $o$-quinones during fermentation. Afoakwa et al. [17] noted that $o$-quinones are highly reactive therefore do polymerize with amino acids, proteins, reducing sugars and other $o$-diphenols to form tannins contributing to the brown colour of the cocoa beans. The reductions in the $o$-diphenols content of the beans during the roasting process might be due to thermal oxidation of the $O$-diphenols into $O$-quinones which then polymerized with other $O$ diphenols, polyphenols, proteins and amino acids to form complexes (tannins), 


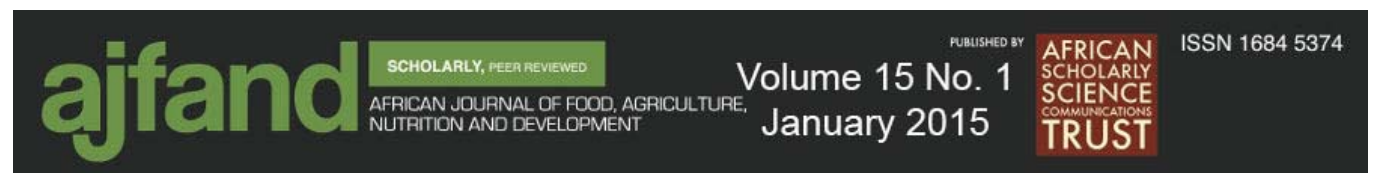

imparting the brown colour of the beans as well as reducing the bitterness of the beans to some extent.

\section{Changes in the antioxidant activity (\% radical scavenging activity) of the cocoa beans}

The decrease in the percentage scavenging activity with increasing pod storage was due to the degradation of the polyphenols in the beans during storage. The decrease in $\%$ free-radical scavenging activities for the unstored pods during roasting might be due to the high polyphenol content in the beans which increased its rate of degradation during the roasting process resulting in reduced $\%$ free-radical scavenging activities. On the other hand, the increase in $\%$ free-radical scavenging activities of the beans whose pods were stored might be due to the formation of other antioxidant compounds such as reductones from Maillard reactions as a result of reduced rate of polyphenol degradation $[21,26]$. These findings suggest that the technique of pod storage as a means of pulp pre-conditioning in cocoa beans could be used to effectively enhance the free radical scavenging activities of the bean prior to fermentation.

\section{CONCLUSION}

Total polyphenols, anthocyanins and $o$-diphenols content of unroasted cocoa beans from the unstored (freshly harvested) pods were $132.248 \mathrm{mg} \mathrm{g}^{-1}, 6.713 \mathrm{mg} \mathrm{kg}^{-1}$ and $15.943 \mathrm{mg} \mathrm{g}^{-1}$, respectively. Increasing pod storage reduced the total polyphenols, anthocyanins and $o$-diphenols content of the unroasted cocoa beans. Roasting further decreased the total polyphenols, anthocyanins and $o$-diphenol content of the beans. Pod storage for 7 days upward was the best period for the reduction in the $\%$ free-radical scavenging activities of the cocoa beans. This was due to the decrease in total polyphenols of the beans with increasing pod storage. Roasting, however, increased the $\%$ free-radical scavenging activities for cocoa beans from pods that were stored but decreased for beans whose pods were not stored prior to fermentation hence, pod storage and roasting are suspected to reduce the astringency and bitterness of cocoa nibs as well as improve the antioxidant activity. Further work is recommended to investigate the effects roasting conditions on the flavour volatile release and character in freshly harvested ad pod stored cocoa beans.

\section{ACKNOWLEDGMENT}

The authors are grateful to Cocoa Research Institute of Ghana, Tafo, Eastern Region, Ghana for supplying all the cocoa pod samples as well as technical support. 


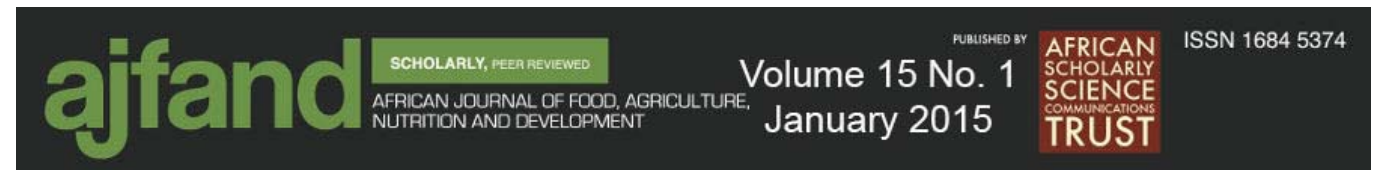

Table 1: Regression coefficients and their $R^{2}$ values in the models for anthocyanins, $O$-diphenols, total polyphenols and $\%$ free-radical scavenging activity of cocoa beans

\begin{tabular}{lllll}
\hline Variables & Polyphenols & Anthocyanin & o-diphenols & $\begin{array}{l}\text { \%Free-radical } \\
\text { scavenging } \\
\text { activity }\end{array}$ \\
\hline Constant & $109.406^{*}$ & $3.8487^{*}$ & $13.1418^{*}$ & $84.9046^{*}$ \\
$\mathrm{X}_{1}$ & $-14.411^{*}$ & $-0.9488^{*}$ & $-2.3460^{*}$ & $-5.0897^{*}$ \\
$\mathrm{X}_{2}$ & $-17.616^{*}$ & $-2.1050^{*}$ & $-1.9289^{*}$ & $-1.4453^{*}$ \\
$\mathrm{X}_{1}{ }^{2}$ & $-18.812^{*}$ & -0.2045 & -0.6609 & $-6.1626^{*}$ \\
$\mathrm{X}_{2}{ }^{2}$ & -0.967 & -0.1955 & $-0.8125^{*}$ & 0.7400 \\
$\mathrm{X}_{1} \times \mathrm{X}_{2}$ & $3.801^{*}$ & $0.5552^{*}$ & $0.5677^{*}$ & $2.8767^{*}$ \\
$\mathrm{R}^{2}$ & $85.9 \%$ & $92.6 \%$ & $83.3 \%$ & $67.4 \%$ \\
$\mathrm{R}^{2}(\operatorname{adj})$. & $84.7 \%$ & $92.0 \%$ & $81.8 \%$ & $64.6 \%$ \\
\hline
\end{tabular}

*Significant at $\mathrm{p}<0.05 ; \mathrm{X}_{1}-$ Pod storage; $\mathrm{X}_{2}$ - Roasting time 


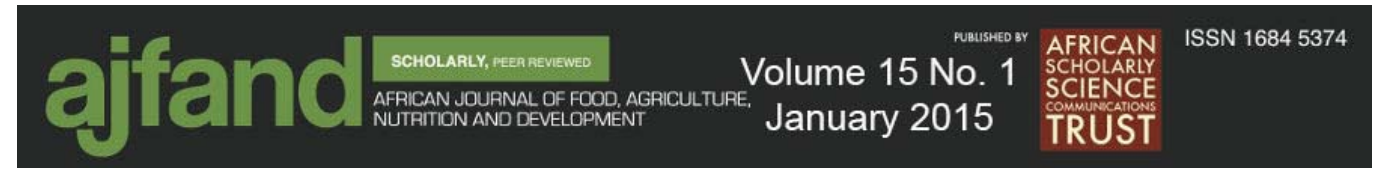

\section{REFERENCES}

1. Wollgast $\mathbf{J}$ and $\mathbf{E}$ Anklam Review on polyphenols in Theobroma cacao: changes in composition during the manufacture of chocolate and methodology for identification and quantification. Food Res Int. 2000; 33: 424-427.

2. Misnawi S and M Sulistyowati Effects of Alkali Concentration and Conching Temperature on Antioxidant Activity and Physical Properties of Chocolate. Int Food Res J. 2008; 15(3): 1.

3. Nazaruddin R, Seng LK, Hassan $O$ and $M$ Said Effect of pulp preconditioning on the content of polyphenols in cocoa beans (Theobroma Cacao) during fermentation. J Indus crops prod. 2006; 24: 87-94.

4. Niemenak N, Rohsius C, Elwers S, Ndoumoua OD and $R$ Lieberei Comparative study of different cocoa (Theobroma cacao L.) clones in terms of their phenolics and anthocyanins contents. J Food Comp Analys. 2006; 19: 612.

5. Afoakwa EO Chocolate science and technology. Wiley-Blackwell publishing. UK. 2010; pp 21-23.

6. Rusconi M and A Conti Theobroma cacao L., the Food of the Gods: a scientific approach beyond myths and claims. Pharmaco Res. 2010; 61: 5-13.

7. Siebert KJ, Troukhanova NV and PY Lynn Nature of polyphenol-protein interactions. J Agric Food Chem. 1996; 44: 80-85.

8. Patras A, Brunton NP, O'Donnell C and BK Tiwari Effect of thermal processing on anthocyanin stability in foods; mechanisms and kinetics of degradation. Trends in Food Sci Technol. 2010; 21: 3-11.

9. Camu N, De Winter T, Addo KS, Takrama JS, Bernaert H and L De Vuyst Fermentation of cocoa beans: influence of microbial activities and polyphenol concentrations on the flavour of chocolate. J Sci Food Agric. 2008; 88: 2288 2297.

10. Thompson SS, Miller KB and AS Lopez Cocoa and coffee. In: Food microbiology_-fundamentals and frontiers. Doyle MJ, Beuchat LR and TJ Montville, (Eds.), Washington, D.C. ASM Press, 2001; pp. $721-733$.

11. Afoakwa EO, Quao J, Budu AS, Takrama JF and FK Saalia Changes in total polyphenols, $O$-diphenols and anthocyanin concentrations during fermentation of pulp pre-conditioned cocoa (Theobroma cacao) beans. Int Food Res J. 2012; 19(3): 1071-1077.

12. Owusu M, Petersen AM and $\mathbf{H}$ Heimdal Relationship of sensory and instrumental aroma measurements of dark chocolate as influenced by fermentation method, roasting and conching conditions. J Food Sci Technol. 2011; 50(5): 1745-4549.

13. Cros E, Villeneueve $\mathbf{F}$ and JC Vincent Evaluation of bitterness and astringency of polyphenolic compounds in cocoa powder. J Food Chem. 1982; 60: 365-370. 


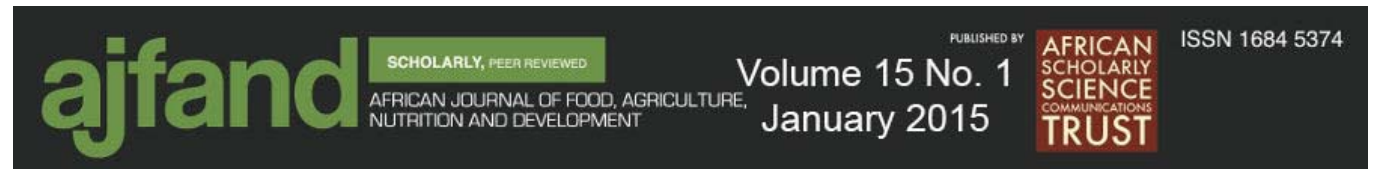

14. Misnawi S, Jinap S, Jamilah B and S Nazamid Oxidation of polyphenols in unfermented and partly fermented cocoa beans by cocoa polyphenol oxidase and tyrosinase, J Sci Food Agric. 2002; 82: 559-566.

15. Othman A, Ismail A, Ghani NA and I Adenan Antioxidant capacity and phenolic content of cocoa beans. J Food Chem. 2007; 100: 1523-1530.

16. Belitz HD, Grosch $\mathbf{W}$ and $\mathbf{P}$ Schieberle Food Chemistry, 4th edn., Springer Verlag, Berlin Heidelberg, 2009; pp 959-967.

17. Afoakwa EO, Quao J, Budu AS, Takrama JF and FK Saalia Effect of pulp pre-conditioning on polyphenolic content and anthocyanin concentrations during fermentation of Ghanaian cocoa beans. Paper Presented at the Annual Meeting of the Institute of Food Technologists (IFT), Ernest Morial Convention Center, New Orleans, L A, USA, June 11 - 14, 2011 (Published Abstract Number 239-01).

18. Charlton AJ, Baxter NJ, Khan ML, Moir AJG, Haslam E, Davies AP and MP Williamson Polyphenol/peptide binding and precipitation. J Agric Food Chem. 2002; 50: 1601-1953.

19. Kattenberg HR and A Kemmink The flavour of cocoa in relation to the origin and processing of the cocoa beans. Deve Food Sci Food Flav, Ingred Comp. $1993 ; 32,1-22$.

20. Delonga K, Jolic' MS, Redovnikovic RI, Markovic' $K$ and D S` ipus ‘ic' Changes of phenolic compounds and antioxidant capacity in cocoa beans processing. Int J Food Sci Technol. 2011; 46: 1793-1800.

21. Summa C, Fernando Cordeiro Raposo CF, McCourt J, Lo Scalzo R, Wagner K, Elmadfa $I$ and $\mathbf{E}$ Anklam Effect of roasting on the radical scavenging activity of cocoa beans. Euro Food Res Technol. 2006; 222: 368 375 .

22. Ngo $\mathbf{T}$ and $\mathbf{Y}$ Zhao Stabilization of anthocyanins on thermally processed red D'Anjou pears through complexation and polymerization. LWT - Food Sci Technol. 2009; 42: 1144-1152.

23. Nadiad J, Bohuon P, Dornier M, Bonazzi C, Perez MA and F Vaillant Effect of water activity on anthocyanin degradation and browning kinetics at high temperatures $\left(100-140^{\circ} \mathrm{C}\right)$. Food Res Int. 2012; 47(1):106-113.

24. Sadilova E, Carle R and FC Stintzing Thermal degradation of anthocyanins and its impact on color and in vitro antioxidant capacity. Mol Nutr Food Res. 2009; 51: 1461-1469.

25. Brownmiller C, Howard LR and RL Prior Processing and storage effects on monomeric anthocyanins, percent polymeric colour, and antioxidant capacity of processed blueberry products. J Food Sci 2008; 5(73): 72-79.

26. Oliviero T, Capuano E, Mmerer B and V Fogliano Influence of roasting on the antioxidant activity and HMF formation of a cocoa bean model systems. J Agric Food Chem. 2009; 57: 147-152. 